\title{
Structural and magnetic characterization of very thin Co-Cr films
}

\author{
Peter ten Berge, Cock Lodder, Steffen Porthun and Theo Popma \\ MESA Research Institute, Unicersity of Twente, P.O. Box 217, 7500 AE Enschede, The Netherlands
}

\begin{abstract}
In this paper we describe the nucleation and growth oi thin $\mathrm{Co}-\mathrm{Cr}$ layers on different substrates and seedlayers. Especially the presence and formation of the initial layer is considered, and corresponding growth mechanisms are proposed. The magnetic properties of these layers have been analyzed by in-plane VSM and by anomalous Hall effect (AHE) measurements. Even layers as thin as $5 \mathrm{~nm}$ are shown to exhibit a perpendicular magnetic anisotropy. For a high coercive Co-Cr film the formation of dot-like domains is shown by the Bitter-colloid/SEM technique.
\end{abstract}

\section{Introduction}

The thickness of $\mathrm{Co}-\mathrm{Cr}$ media for perpendicular recording has been reduced by a factor 10 during the last decade and is nowadays in the order of $0.15 \mu \mathrm{m}$. Their recording performance depends strongly on the microstructure, morphology and chemical inhomogeneities of the films. In most papers concerning thin film (perpendicular) recording media, the macroscopic magnetic parameters are used to explain the behaviour. However, for recording applications the upper part of these thin films, mostly considered magnetically homogeneous, becomes more important [1-4]. Using a thickness of only about $0.15 \mu \mathrm{m}$, it seems to be more logical to consider the effect of changing properties in the thickness direction of the film into the macroscopic behaviour of films: if the first (atomic) layers of material at the substrate (the so-called initial layer) show deviating magnetic behaviour, they will contribute relatively strong to the overall properties. Therefore it is necessary to investigate the way that the magnetic properties of the initial layer affect those of the layers with a thickness of $0.10-0.15 \mu \mathrm{m}$.

Correspondence to: Dr. J.C. Lodder, MESA Research Institute. University of Twente, P.O. Box 217, 7500 AE Enschede, The Netherlands.
Several authors have reported on the existence and the properties of initial layers in $\mathrm{Co}-\mathrm{Cr}$ films [5-11]. For clarity reasons the definition of an initial layer as it is used in this paper is given here: the initial layer in a $\mathrm{Co}-\mathrm{Cr}$ film is the part of the layer that is closest to the substrate, where the crystal orientations are random in the sense that the hexagonal $c$-axis is randomly distributed in the plane of the film, while the well-known columnar structure has not developed yet. It has been shown that the magnetic properties and structural properties can be improved by the use of appropriate substrates or seedlayers, such as $\mathrm{Ti}, \mathrm{Si}$ and $\mathrm{Ge}$ [5-8]. Several authors have adapted a sublayer (a division of one layer into several) model [9-11], by which they have explained the change in thickness direction of the perpendicular coercivity, the saturation magnetization and the hexagonal $c$-axis dispersion; this variation in thickness direction was found to influence the magnetization reversal mechanism, as concluded from magnetization curves [11] and recording experiments [12].

In this paper we discuss several structural and magnetic properties of a thickness series of $\mathrm{Co}-\mathrm{Cr}$ films in the range of $5-200 \mathrm{~nm}$ on different substrates and seedlayers. The paper deals with several aspects of these thin $\mathrm{Co}-\mathrm{Cr}$ films. First the structure of the films is discussed froin the viewpoint of their nucleation and growth mecha- 
nism. This gives us a starting point to consider the influence of the initial layer on the macroscopic magnetic properties, as they are expressed by the in-plane remanence ratio $\left(M_{\mathrm{r}} / M_{\mathrm{s}}\right)_{\|}$. In the second part of this paper this property will be shown as a function of the film thickness. In the second part also a comparison is made between the hysteresis measurements as they are performed with a vibrating sample magnetometer (VSM) and an anomalous Hall effect (AHE) measurement setup [13]. The first one (VSM) obviously is a bulk measurement technique, while the second technique (AHE) supplies information about the orientation of the magnetic moment of very thin films, since the measured Hall signal is inversely proportional to the film thickness [13]. Also torque measurements have been performed. The last part shows the domain patterns of a higil coercive sample, as visualized by means of the Bitter colloid technique, combined with a scanning electron microscope.

\section{Preparation of the samples}

The Co-Cr films that are described in this paper have all been prepared by rf sputtering in a Leybold-Heraeus Z40 vacuum system. The substrates and scedlayers that are used here are shown in table 1.

The alloyed target (Materials Research Company) contains about 19 at.\% $\mathrm{Cr}$ and has a diameter of $10 \mathrm{~cm}$. The $\mathrm{rf}$ voltage during sputter deposition was $1600 \mathrm{~V}$, and the deposition rates of $\mathrm{Co}-\mathrm{Cr}$ and $\mathrm{Ge}$ were 0.22 and $0.27 \mathrm{~nm} / \mathrm{s}$,

Table 1

Overview of substrates and seedlayers used in this study

\begin{tabular}{|c|c|c|}
\hline Substrate & Seedlayer(s) & $\begin{array}{l}\text { Pieparation method } \\
\text { seedlayer }\end{array}$ \\
\hline Si(íioj) & - & - \\
\hline $\operatorname{Si}(111)$ & - & - \\
\hline $\operatorname{Si}(100)$ & $\mathrm{Si}_{3} \mathrm{~N}_{4}$ & LPCVD \\
\hline $\operatorname{Sil}(00)$ & $\mathrm{Ge}$ & $\begin{array}{l}\text { rf sputtering } \\
\text { (diff. conditions) }\end{array}$ \\
\hline $\mathrm{Si}(100)$ & $\mathrm{SiO}_{2} / \mathrm{Ge}$ & $\begin{array}{l}\text { thermal oxid. } \\
\text { /rf sputtering }\end{array}$ \\
\hline Glass (Corning 7059) & $\mathrm{Ge}$ & rf sputtering \\
\hline
\end{tabular}

respectively. The samples prepared by "rf sputtering" (diff. conditions) in table 1 are different in the way the plasma is applied: samples denoted $\mathrm{Ge}(1) / x \mathrm{~nm} \mathrm{Co}-\mathrm{Cr}$ were prepared by slowly increasing the rf-voltage from zero to 1600 $\mathrm{V}$ in $10 \mathrm{~s}$ (corresponds to $2.2 \mathrm{~nm}$ ), while samples denoted $\mathrm{Ge}(2) / x \mathrm{~nm} \mathrm{Co}-\mathrm{Cr}$ were prepared, as all others, with a constant voltage of $1600 \mathrm{~V}$. The background pressure was about $1 \times 10^{-7}$ mbar, and the argon pressure during sputter deposition was $1.4 \times 10^{-2}$ mbar. The silicon oxide layers have been prepared by thermal oxidation at $1150^{\circ} \mathrm{C}$ (thickness about $50 \mathrm{~nm}$ ) and the silicon nitride layers (thickness about $40 \mathrm{~nm}$ ) have been prepared by low pressure chemical vapour deposition (LPCVD) $[14,15]$. The silicon oxide and the silicon nitride layers have been exposed to the atmosphere prior to the sputter deposition of $\mathrm{Ge}$ and $\mathrm{Co}-\mathrm{Cr}$. The $\mathrm{Ge}$ and $\mathrm{Co}-\mathrm{Cr}$ layers have subsequently been deposited in situ. A glow discharge cleaning has been applied to all substrates/seedlayers before every sputter deposition. The Ge layer thickness is about $30 \mathrm{~nm}$ (as checked by EDX). Unless explicitly stated otherwise, the film thicknesses mentioned in this paper have all been calculated from the calibrated sputter deposition time.

\section{Introduction on the nucleation and growth of Co-Cr layers}

The interaction between the substrate and the impinging atoms/clusters during the deposition process determines the subsequent growth mechanism (see for instance ref. [16]). In general three growth modes are considered [16]. When the interaction energy (adhesion) between the atoms of the deposit and substrate is high compared to the cohesion of the deposit atoms, a layer by layer growth mechanism (2D) will dominate (FrankVan der Merwe, or F-M). On the other hand, when the cohesion of the deposit atoms is much higher than the adhesion between the substrate and the deposit atoms, the growth will take place through island formation (3D, Volker-Weber, or $\mathrm{V}-\mathrm{W})$. In case the interaction energy difference between the cohesion and adhesion is not that 
pronounced, the growth takes place by formation of a layer (or a few layers), followed by three-dimensional island growth; this third growth mechanism is called Stranski-Krastanov (S-K) growth. This type of growth is often explained by including elastic lattice distortions in the consideration of the energy of the deposit layer. The initial stage of growth establishes a lattice relaxation of the deposit in order to reduce the misfit between deposit and substrate. The transition to island growth takes place because the total energy becomes smaller if the adhesive forces have a smaller range than the elastic forces [16].

In the case of sputtered $\mathrm{Co}-\mathrm{Cr}$ films it is proposed that, under optimized conditions, with some substrates/seedlayers a sort of reaction layer is formed [17], i.e. Ti, C, and amorphous $\mathrm{Si}$ or $\mathrm{Ge}$. In ref. [8] it is suggested that the interac-
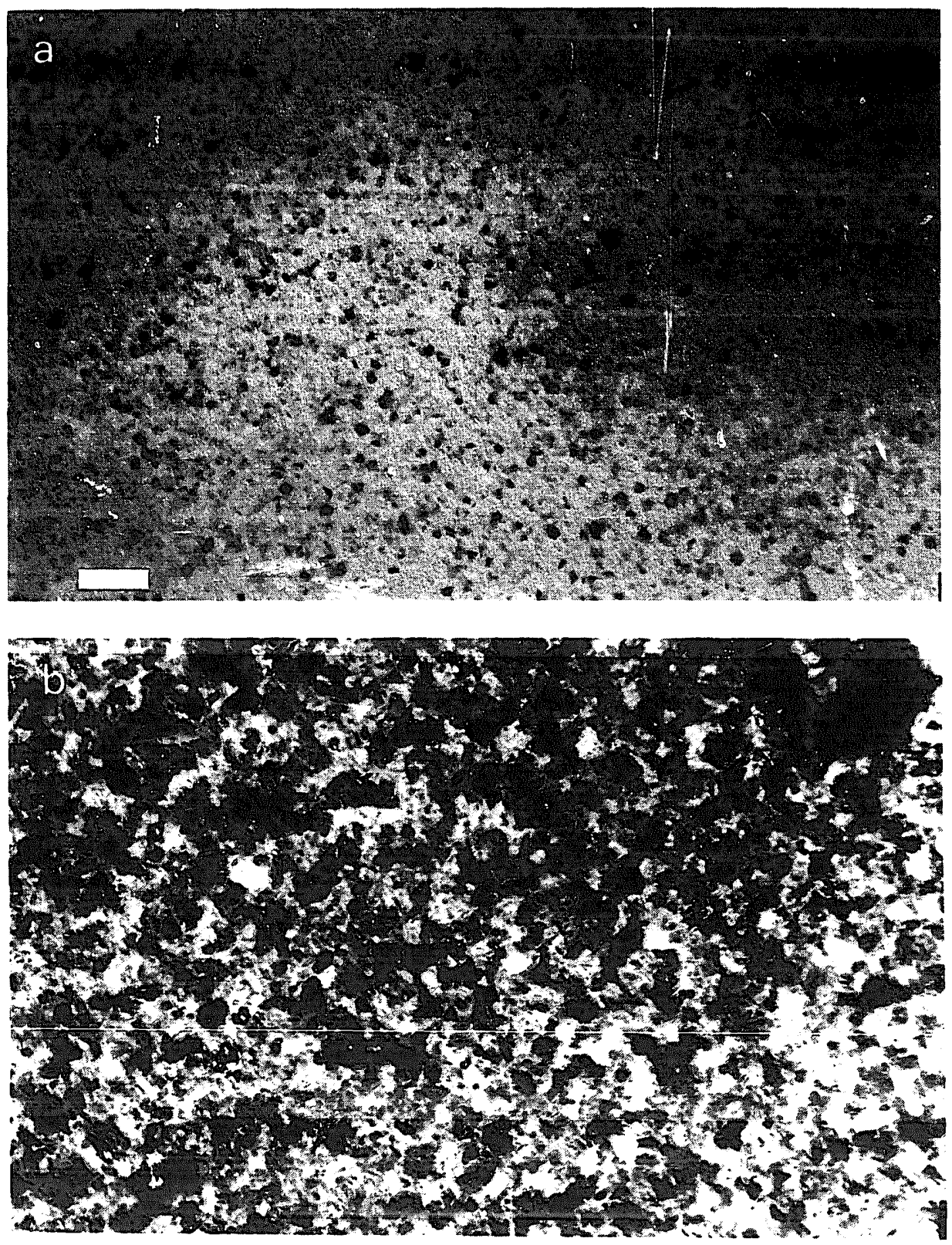

Fig. 1. BF TEM images of (a) $\mathrm{Si} / \mathrm{Si}_{3} \mathrm{~N}_{4} / 10 \mathrm{~nm} \mathrm{Co}-\mathrm{Cr} ; \mathrm{Si} / \mathrm{Si}_{3} \mathrm{~N}_{4} / 100 \mathrm{~nm} \mathrm{Co}-\mathrm{Cr}$, bar $=50 \mathrm{~nm}$. 
tion between a $\mathrm{Co}-\mathrm{Cr}$ film and a $\mathrm{Ge}$ seedlayer consists of a sort of epitaxial-like growth mechanism on the $\mathrm{Ge}(110)$ and $\mathrm{Ge}(111)$ planes, present in the form of microareas in an amorphous $\mathrm{Ge}$ matrix. However, the AES depth profile analysis shows the formation of silicides [17] (i.e. a region containing silicon, cobalt and chromium). In ref. [18] it is found that the solid solubility of Co in silicon is larger than that of $\mathrm{Cr}$, as also stated in ref. [17], but the diffusion coefficient of $\mathrm{Cr}$ in silicon is larger than that of Co in silicon. Also, at relatively low temperatures $\left(T<900^{\circ} \mathrm{C}\right)$, the metal is the dominant diffuser in silicon, instead of otherwise. Furthermore, the heat of formation of $\mathrm{MSi}_{x}$ (with $x=\frac{1}{2}, 1,2$ ) is larger with $\mathrm{M}=\mathrm{Cr}$ for $x=2$ than with $\mathrm{M}=\mathrm{Co}$, but smaller for $x=\frac{1}{2}$ or 1 . Thus, it is reasonable to assume that the cobalt and chromium silicides will form the reaction layer in about an equal ratio. If the reaction layer is responsible for the observed improved oriented growth on silicon, the same improvement, found on $\mathrm{Ti}, \mathrm{Ge}$ and $\mathrm{C}$ layers supports an extrapolation of the silicide formation to titanide, carbide and germanide formation. More evidence on this is given in a report by Schrauwen et al. [19], excluding the possibility of a sort of epitaxial growth by
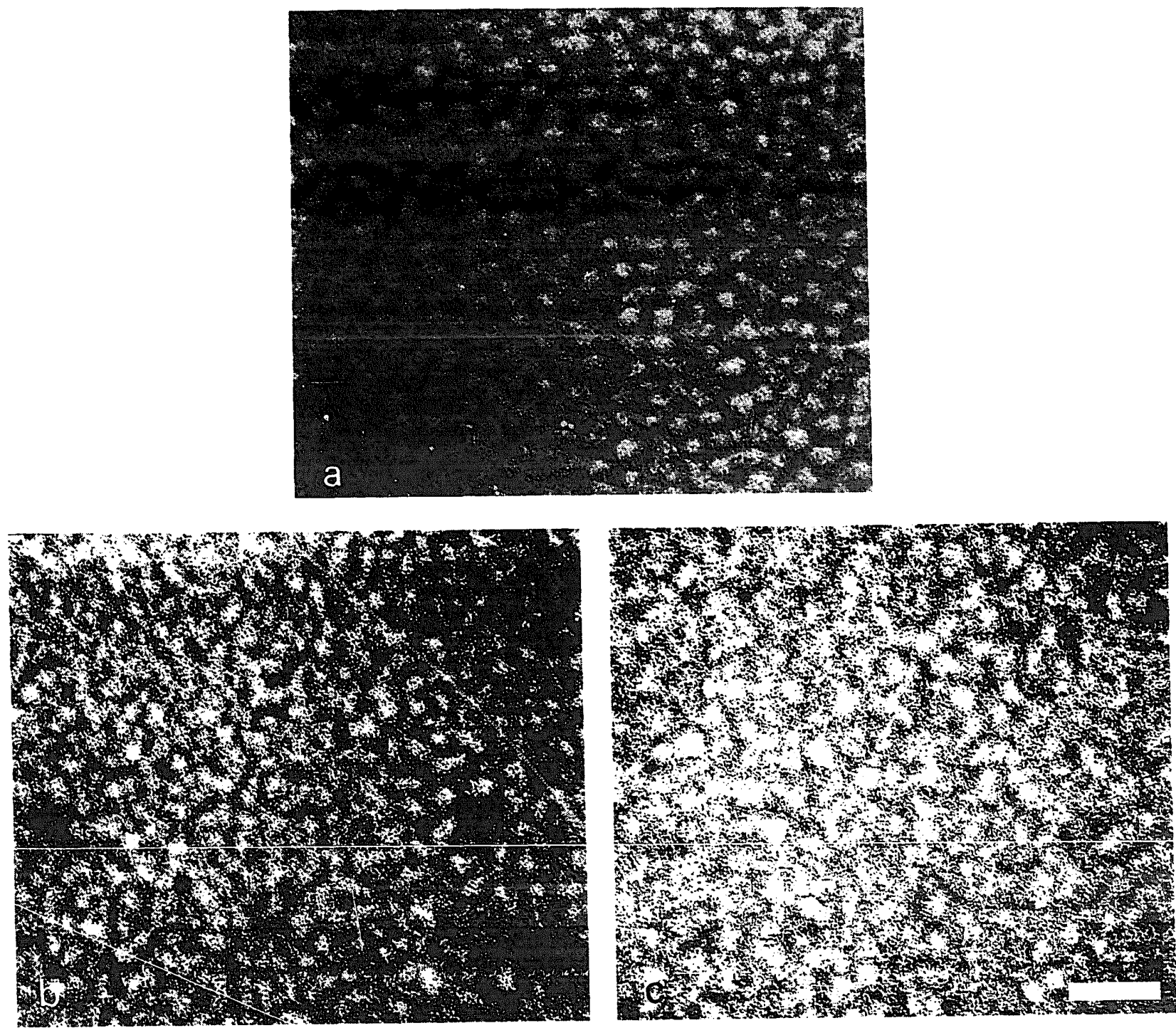

Fig. 2. SEM photographs of $100 \mathrm{~nm} \mathrm{Co-Cr} \mathrm{films} \mathrm{on} \mathrm{(a)} \mathrm{Si}(100)$, (b) $\mathrm{Si}_{3} \mathrm{~N}_{4}$ and (c) $\mathrm{Ge}(1)$. The marker corresponds to $125 \mathrm{~nm}$. 
considering the effect of lattice (mis)match on the $\Delta \theta_{50}$-values for different lattice planes of $\mathrm{Ge}$. In the reaction layer these (silicide etc.) compounds would then be formed during the initial stage of the sputter deposition. The layer probably acts as a lattice-misfit relieving layer and also as a nucleation layer that does not exhibit any microroughness, on which subsequent oriented growth takes place. Experiments that did not incorporate this reaction layer, thus not compensating for the microroughness, resulted in a worse oriented layer (as shown by their respective $\Delta \theta_{50}$-values [17]). This reaction layer-type of growth is a form of Stranski-Krastanov growth.

\section{Experimental results}

\subsection{Nucleation and growth}

As we have seen above, certain seedlayers or substrates induce the desired growth of $\mathrm{Co}-\mathrm{Cr}$ layers, and several authors have adopted the Stranski-Krasta' ov growth mechanism to be responsible for it. Another substrate not known for such behaviour, $\mathrm{Si}_{3} \mathrm{~N}_{4}$, has also been investigated here; in fig. 1 the bright field TEM micrograph of two Co-Cr films of 10 and $100 \mathrm{~nm}$ thickness on a silicon nitride seedlayer are shown (planar view). Fig. 1a shows a continuous layer already, indicating, that possible island formation in the initial stage of growth proceeds to a thickness less than $10 \mathrm{~nm}$. As mentioned in ref. [9] the $c$-axis dispersion can be constant through the entire film, or in other words, the $c$-axis dispersion of the firstly deposited layers is inherited by the subsequently deposited layers. In our films the $\Delta \theta_{50}$-values for the three Co-Cr films $(d=100 \mathrm{~nm})$ on different seedlayers are given in table 2.

Table 2

Dispersion of (00.2) planes of $100 \mathrm{~nm} \mathrm{Co-Cr}$ films on several substrates (or seedlayers)

\begin{tabular}{lcl}
\hline Substrate & $\Delta \theta_{50}$ & Growth mechanism \\
\hline $\mathrm{Si}(100)$ & 2.8 & Stranski- $\mathrm{N}$ rastanov \\
$\mathrm{Si}(100) / \mathrm{Ge}(1)$ & 13.5 & Volker-Weber \\
$\mathrm{Si}(100) / \mathrm{Si}_{3} \mathrm{~N}_{4}$ & 14.0 & Volker-Weber \\
\hline
\end{tabular}

Table 3

Comparison of $\Delta \theta_{50}$ and in-plane remanence ratio

\begin{tabular}{rll}
\hline Thickness [nm] & $\Delta \theta_{50}$ & $\begin{array}{l}\text { In-plane remanence } \\
\text { ratio }\end{array}$ \\
\hline 5 & 3.4 & 0.23 \\
25 & 2.8 & 0.32 \\
50 & 2.7 & 0.18 \\
100 & 2.8 & 0.09 \\
\hline
\end{tabular}

For the $\mathrm{Si}(100)$ and for the $\mathrm{Si}_{3} \mathrm{~N}_{4}$ films only a very slight improvement of the $\Delta \theta_{50}$-values has been measured as a functioii of thickness (see also table 3 for a $\mathrm{Si}(100)$ series). However, the initial growth mechanism has been different for these $\mathrm{Co}-\mathrm{Cr}$ films, assumed that the $c$-axis dispersion at a thickness of $100 \mathrm{~nm}$ is inherited from the initially grown layer, as in ref. [9]. Considering this together with a possible island formation on inert substrates/seedlayers or a silicide reaction layer, we have tentatively distinguished between the $\mathrm{V}-\mathrm{W}$ growth and $\mathrm{S}-\mathrm{K}$ growth mechanism in table 2 .

In fig. 2 the SEM topview pictures of the films in table 2 are shown. The columns, as far as present, dif in diameter and shape: the $\mathrm{Si}(100) / \mathrm{Co}-\mathrm{Cr}$ film has a high density of columns with a diameter of about $50 \mathrm{~nm}$; the $\mathrm{Si}(100) /$ $\mathrm{Si}_{3} \mathrm{~N}_{4} / \mathrm{Co}-\mathrm{Cr}$ film seems to be less dense packed with smaller columns of about $30 \mathrm{~nm}$, while the $\mathrm{Si}(100) / \mathrm{Ge}(1) / \mathrm{Co}-\mathrm{Cr}$ film consists of very irregularly shaped "columns". The first two Co-Cr films have been prepared in an identical way, while the $\mathrm{Ge}(1)$ seedlayer $\mathrm{Co}-\mathrm{Cr}$ film was prepared differently as described above. Since the films have been prepared in an identical manner, excent for the firstly deposited atomic layers $(2.2$ $\mathrm{nm}$ of $100 \mathrm{~nm}$ total), the difference in morphology on the top should originate from initial growth effects. Thi ; also indicates that the growth mechanisms may initially vary for these films, as we proposed ayove. Another example of the strong effect of the initial way of growth is given in the next part.

Although the $\Delta \theta_{50}$-values do show the degree of orientation of the $c$-axis normal to the film plane, they do not supply unambiguous information about the initial layer: the crystals that are 
totally out of the normal orientation, e.g. the (100) and (101) orientations, have no effect on $\Delta \theta_{50}$ [20]. In fig. 3 it is shown by selected area electron diffraction (SAED)-patterns of the planar view samples that these orientations indeed are present in our $\mathrm{Si}_{3} \mathrm{~N}_{4}$-substrate films, and consequently do have an effect on the anisotropy. The development of the intensities with thickness shows an improvement of the orientation of the crystallites towards the (10.0) direction, thus improving the crystalline uniaxial anisotropy. The corresponding bright field TEM micrographs of the 10 and $100 \mathrm{~nm}$ films in fig. 3 have already been given in $f .8$.

The next part, correlating the initial layer and the magnetic properties, deals with the in-plane remanence ratio's of our films and will give the supplementary information to the $\left.\Delta \theta_{50}\right)^{-}$values.

\subsection{Magnetic properties of the initial layer}

From section 4.1 it is clear that the type of substrate has a major influence on the formation of an initial layer as well as on the structure of the bulk layer on top of the initial layer. This part considers the magnetic properties of the films. As already stated, the in-plane remanence ratio, derived from the in-plane VSM measurements, supplies additional information to the $\Delta \theta_{50}$-values: the in-plane remanence ratio is determined by all (misoriented) crystals that have their magnetic moments not in the perpendicular direction [20].

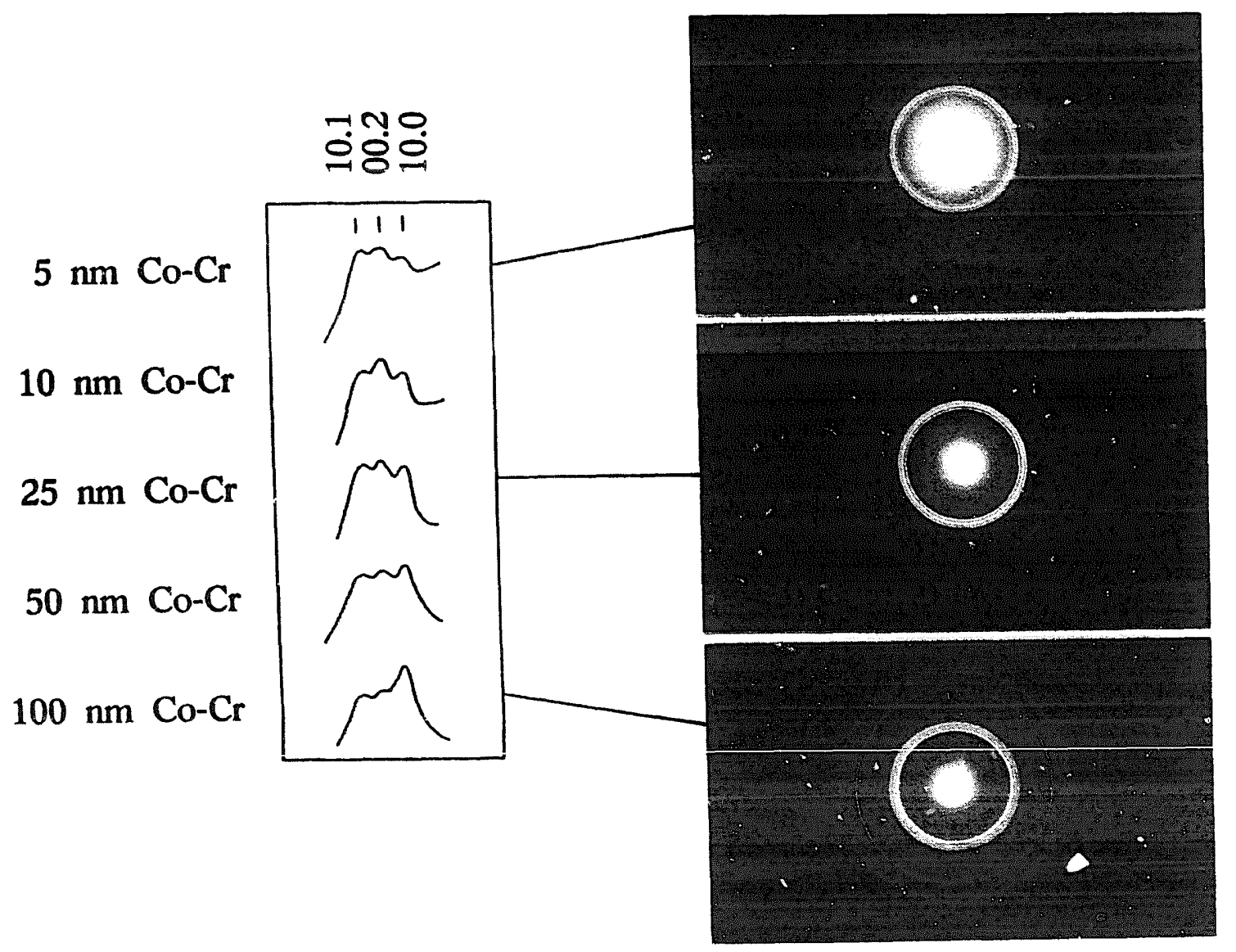

Fig. 3. Development of SAED intensities as a function of $\mathrm{Co}-\mathrm{Cr}$ film thickness (on $\mathrm{Si}_{3} \mathrm{~N}_{4}$ ). 

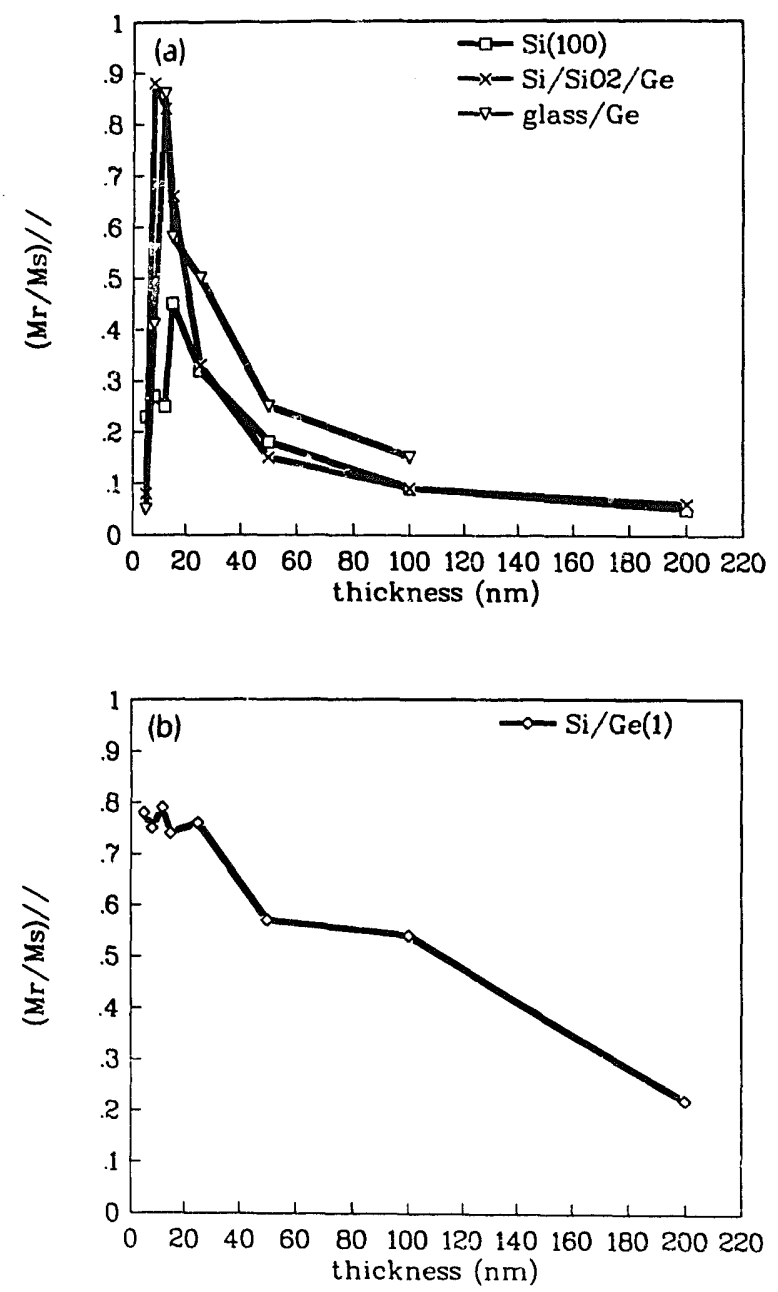

Fig. 4. In-plane remanence ratio $\left(M_{\mathrm{r}} / M_{\mathrm{r}}\right)$ vs. $\mathrm{Co}-\mathrm{Cr}$ layer thickness on (a) $\mathrm{Si}(100), \mathrm{Si}(100) / \mathrm{SiO}_{2} / \mathrm{Ge}$ and glass $/ \mathrm{Ge}$ and on (b) $\mathrm{Si}(100) / \mathrm{Ge}(1)$.

In table 3 another example of this non-linear dependence of $\Delta \theta_{50}$ and the in-plane remanence ratio is given, based on our measurements on $\mathrm{Si}(100) / x \mathrm{~nm}$ Co-Cr films.

Thus in addition to the crystallographic anisotropy information derived from the $\Delta \theta_{50}$-values, the in-plane remanence ratio gives a measure of the in-plane magnetic anisotropy in all orientations. In fig. 4 the in-plane remanence ratio is shown as a function of thickness for sevcral substrates and seedlayers.

The in-plane remanence ratio shows the same general behaviour for all substrates/seedlayers (fig. 4a) except for the $\mathrm{Si} / \mathrm{Ge}$ (1) series (fig. 4b). Initially it increases and after reaching a maxi- mum it falls again. This indicates that the thinnest Co-Cr films $(d<10 \mathrm{~nm})$ contain relatively more crystals that have their magnetic moments in the perpendicular direction than films just above 10 $\mathrm{nm}$. Thicker films $(d>50 \mathrm{~nm})$ show an improvement of the perpendicular orientation of the magnetic moment, as has also been shown in ref. [5]. In order to support this, measurements of the anomalous Hall effect (AHE) have been undertaken. The AHE signal is proportional to the magnetization component perpendicular to the film plane, and is inversely proportional to the thickness of the film [13]. In figs. 5a and b the in-plane hysteresis loops of two films are shown. In figs. 5c and $d$ the AHE curves for the same samples are displayed.

The $5 \mathrm{~nm} \mathrm{Co-Cr}$ film has an in-plane remanence ratio of 0.05 , while the $8 \mathrm{~nm}$ film showed a value of 0.88 , as measured from the in-plane hystereses. The AHE curves have been measured with an angle of $10^{\circ}$ between the applied field and the film plane, in order to have an effective external field on both the in-plane and perpendicular magnetization components. From fig. 5c, taken from the $5 \mathrm{~nm} \mathrm{Co-Cr}$ sample, it can be seen that, coming from positive high fields, at small applied fields the magnetization comes out of the (film) plane; going to negative field values, we initially observe the switched magnetization, and it is forced into the film plane again at higher fields. In contrast, fig. 5d, taken from the $8 \mathrm{~nm}$ $\mathrm{Co}-\mathrm{Cr}$ sample, does not show this feature at all. This result is in complete agreement with the measurements of the in-plane remanence ratios of these samples.

In the literature [2i] it is found that the inplane remanence ratio is related to the in-plane orientated magnetic moments that are located in domain walls. The authors have calculated and experimentally shown that for films on a Ge underlayer with a fixed coercivity the in-plane remanence ratio exhibits a maximum at low thicknesses. The calculation is based on the size of the domain period, derived from the Kooy and Enz model [22], and the domain period is inversely proportional to the in-plane remanence ratio, with the assumption that the in-plane oriented magnetic moments are solely located in the domain 

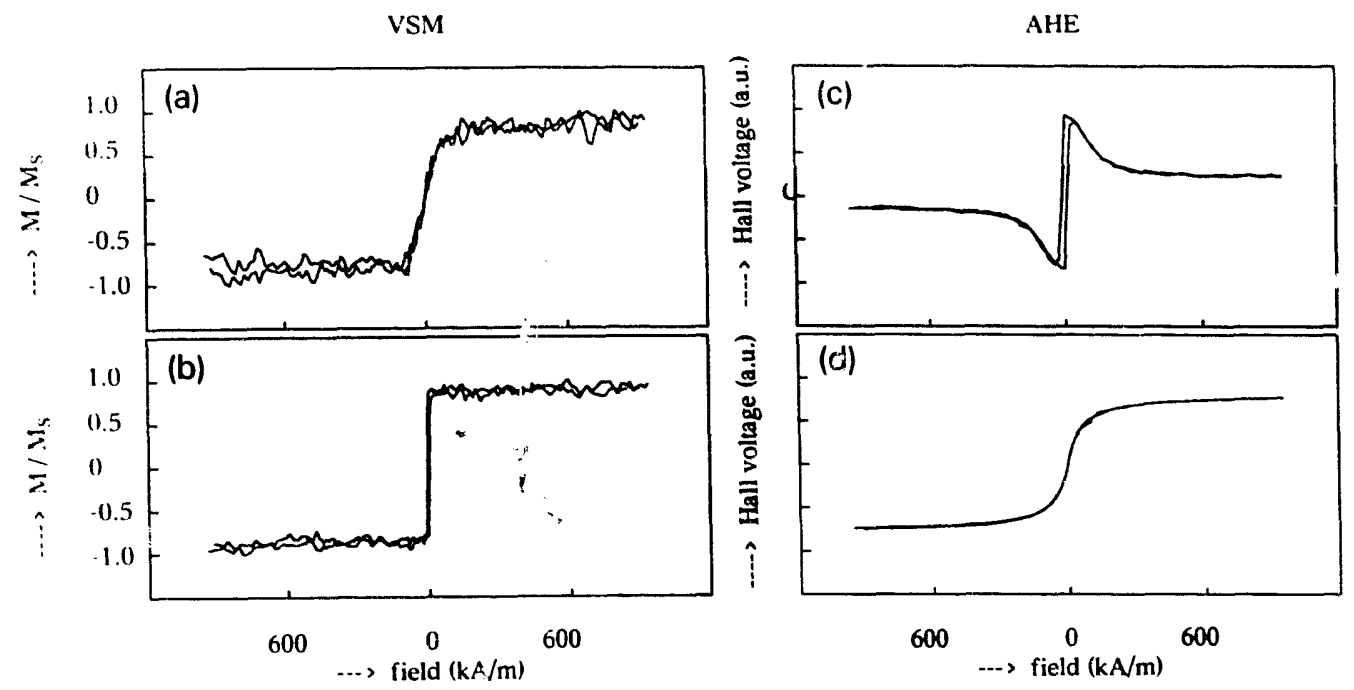

Fig. 5. VSM in-plane hysteresis loops of (a) $5 \mathrm{~nm} \mathrm{Co-Cr}$ and (b) $8 \mathrm{~nm} \mathrm{Co}-\mathrm{Cr}$ on $\mathrm{Si}(100) / \mathrm{SiO}_{2} / \mathrm{Ge}$ and the corresponding $\mathrm{AHE}$ curves of (c) $5 \mathrm{~nm} \mathrm{Co}-\mathrm{Cr}$ and (d) $8 \mathrm{~nm} \mathrm{Co-Cr}$.

walls. The agreement between calculation and experiment was reasonable, especially for low coercive films, since the Kooy and Enz model does not include coercivity. Most of our films, although they have a changing coercivity as a function of thickness, show the same behaviour as depicted above. Thus, the behaviour in fig. 4 is at least partly explained. An additional factor, contributing to the in-plane remanence ratio, is the existence of an initial layer. An initial layer in a $\mathrm{Co}-\mathrm{Cr}$ film exhibits itself as a "jump" in the in-plane hysteresis loop. In fact, now the in-plane
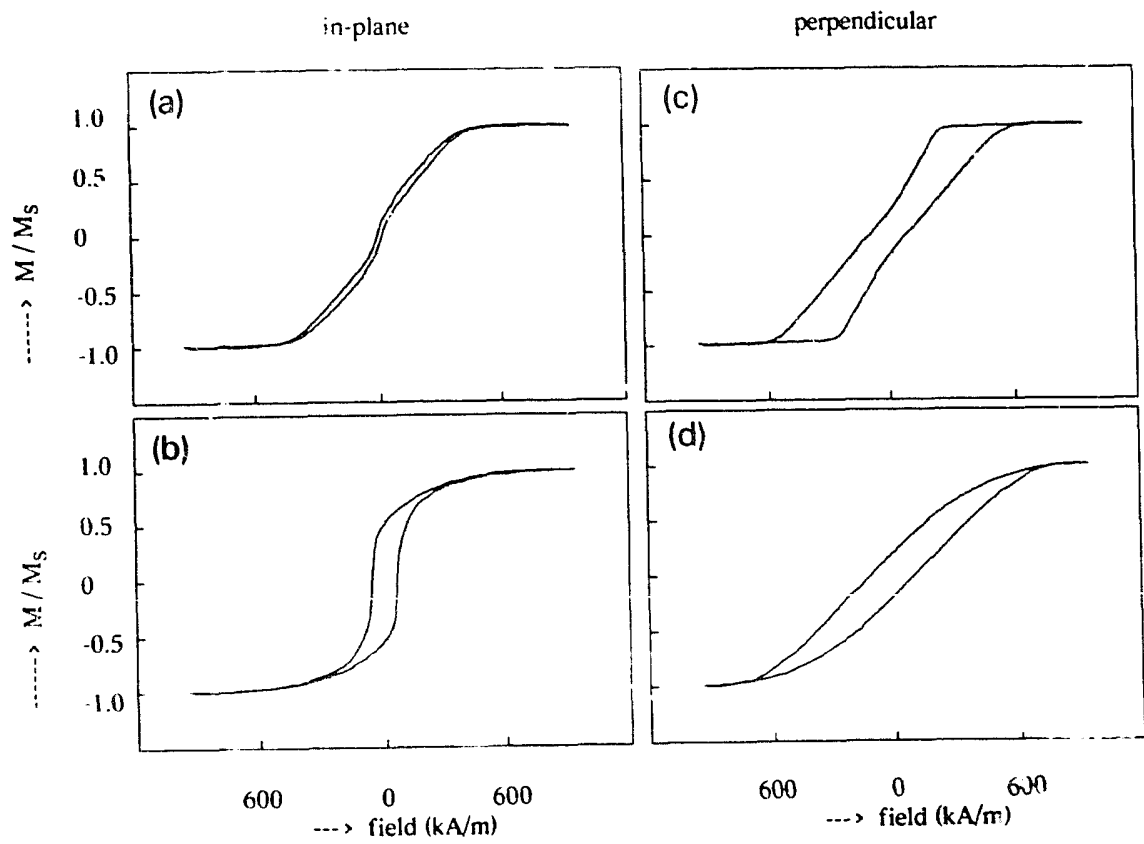

Fig. 6. VSM hysteresis loops of $109 \mathrm{~nm} \mathrm{Co}-\mathrm{Cr}$ on Si/Ge(1) (b, d) and Si/Ge(2) (a, c). 
hysteresis loop is a superposition of the hysteresis of the initial layer and the hysteresis of the top layer. The initial layer loop is then measured along its easy axis, while the top layer loop is a hard axis loop, tilted for the demagnetization. Thus, any film containing an initial layer will exhibit an (easy axis) jump in the in-plane hysteresis loop. Films that do exhibit an initial layer will thus not show a maximum in-plane remanence ratio as a function of thickness. So, with increasing thickness the in-plane remanence ratio will only decrease for films with an initial layer. Now we can distinguish our films in two types: films without initial layer, showing a maximum in the in-plane remanence ratio as a function of thickness, and films with an initial layer, showing a decreasing in-plane remanence ratio with thickness. The $\mathrm{Si} / \mathrm{Ge}(1)$ series in fig. $4 \mathrm{~b}$ is an example of the latter type. The difference of the $\mathrm{Si} / \mathrm{Ge}(1)$ series compared to the other series in fig. $4 \mathrm{a}$ is probably the result of the different preparation procedure of the films. In this case the initial rf voltage (during the first ten seconds of sputter deposition) was increased from zero to $1600 \mathrm{~V}$, as mentioned above, resulting in a lower energy of the impinging atoms or clusters. This energy may be too low for the formation of reaction layer consisting of cobalt-germanides, as described above. Then the growth mechanism would not be of the S-K type, but rather a V-W type of
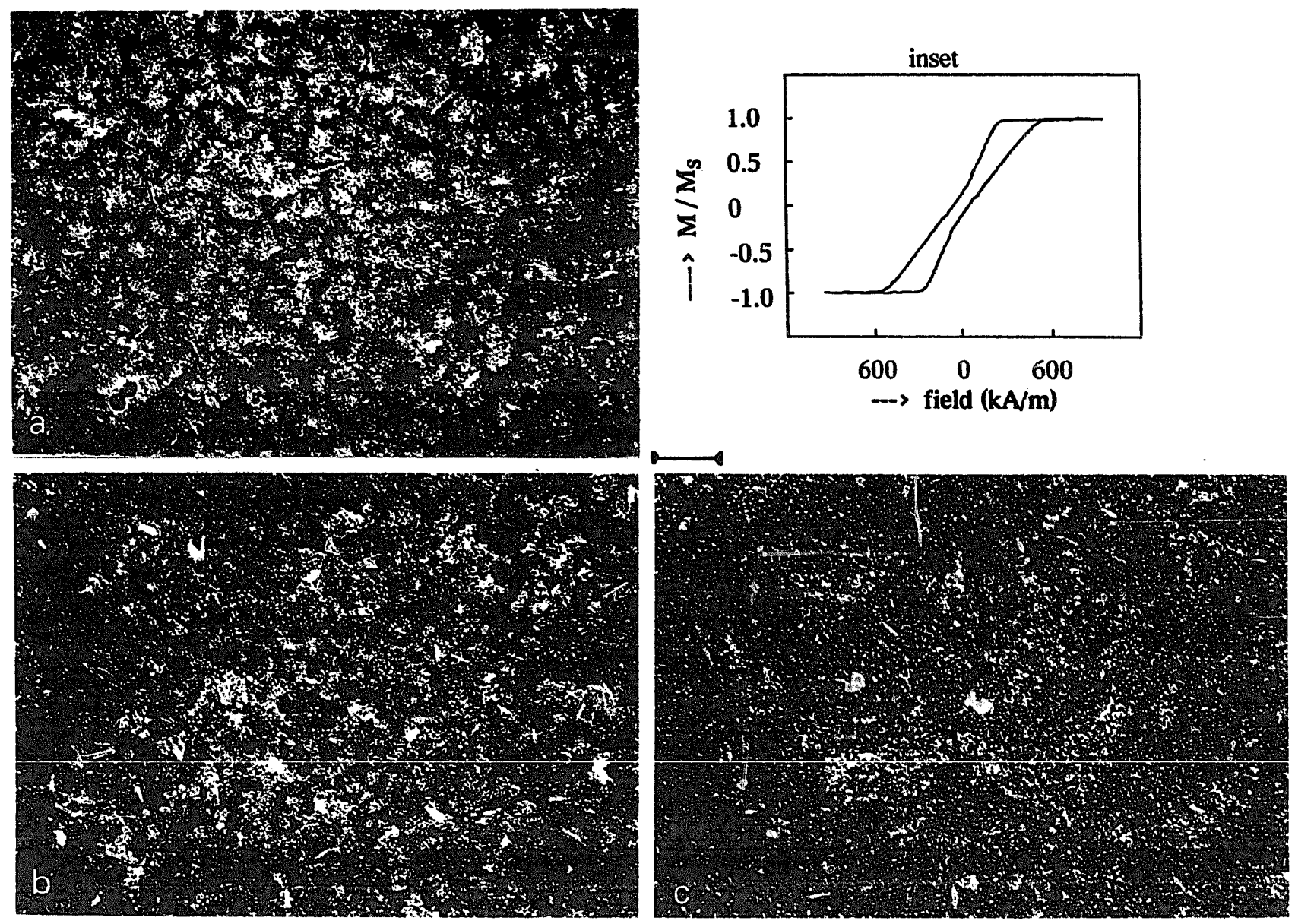

Fig. 7. Domain patterns of $100 \mathrm{~nm} \mathrm{Co-Cr} \mathrm{film} \mathrm{on} \mathrm{Ge}$ at (a) $H_{\mathrm{c} \perp}$, (b) $-240 \mathrm{kA} / \mathrm{m}$ and (c) $-640 \mathrm{kA} / \mathrm{m}$. the marker corresponds to $500 \mathrm{~nm}$; inset: corresponding perpendicular hysteresis. 
mechanism. As suggested earlier, this gives a worse crystalline orientation of the initial layer, and results in a higher value of the $\left(M_{\mathrm{r}} / M_{\mathrm{s}}\right)_{\text {. }}$.

In fig. 6 the in-plane and perpendicular hysteresis loops of the $\mathrm{Si} / \mathrm{Ge}(1)$ and $\mathrm{Si} / \mathrm{Ge}(2)$ seedlayer with $100 \mathrm{~nm} \mathrm{Co-Cr}$ are shown. Except for the first ten seconds these films were prepared identically.

The perpendicular loops of both samples indicate a different reversal mechanism, while the in-plane curves show a difference in the orientation of the magnetization. The $\left(M_{\mathrm{r}} / M_{\mathrm{s}}\right)_{\|}$for $\mathrm{Si} /$ $\mathrm{Ge}(1)$ is 0.54 and for $\mathrm{Si} / \mathrm{Ge}(2)$ is 0.10 . Furthermore, from torque measurements it is derived that their crystalline anisotropy $\left(K_{1}\right)$ is 49.5 and $222.9 \mathrm{~kJ} / \mathrm{m}^{3}$, respectively; their values for $Q$, defined as $K_{1} / K_{\mathrm{d}}$ (with $K_{\mathrm{d}}=\frac{1}{2} \mu_{0} M_{\mathrm{s}}^{2}$ ) and indicating the degree that the crystalline anisotropy energy is able to overcome the demagnetization energy, are 0.27 and 0.90 , respectively. This again shows the tremendous effect of the initial stage of growth on the resulting properties of the film.

\subsection{Domain patterns of high coercice films}

We have used the Bitter colloid technique, combined with a scanning electron microscope, to visualize the natural domain patterns of a $100 \mathrm{~nm}$ thick $\mathrm{Co}-\mathrm{Cr}$ film on $\mathrm{Ge}$. This technique is strongly determined by the surface magnetic properties of the sample. In fact, the same stray fields that are sensed by the recording head determine the visualized domain pattern. So, these domain patterns have a strong correlation with actual recording properties. This is also reflected in the difficulty that is experienced in obtaining high resolution domain patterns of high coercive samples by this technique, compared to low coercive samples [23]; the recording properties of higit coercive $\mathrm{Co}-\mathrm{Cr}$ samples are superior over those of low coercive films [12], implying a difference in stray field configuration above the film surface. In fig. 7 the domain patterns of a $100 \mathrm{~nm} \mathrm{Co-Cr} \mathrm{film} \mathrm{at} \mathrm{three}$ different field values are shown. The inset shows the field values in the perpendicular hysteresis loop of the film $\left(H_{\mathrm{c} \perp}=47.5 \mathrm{kA} / \mathrm{m}\right)$.

It can be seen in fig. $7 \mathrm{~b}$ that at intermediate fields small dot-like domains have developed with a size of about $100 \mathrm{~nm}$. Dot-like domains have been measured earlier by the enhanced Kerr microscopy technique for high $H_{\mathrm{c}}$ films, as well as stripe domains for low $H_{\mathrm{c}}$ films [24]. We have not observed any stripe domain formation in this film, such as has been reported in refs. [23,24].

\section{Conclusion}

In this paper we have investigated thickness series of $\mathrm{Co}-\mathrm{Cr}$ films in the range $5-200 \mathrm{~nm}$ on several substrates and seedlayers. The initial growth process of the $\mathrm{Co}-\mathrm{Cr}$ strongly determines the $c$-axis dispersion (tables 2 and 3 ), the orientation of the easy axis of magnetization (figs. 4 and 5) and the crystalline anisotropy of the whole film. We suggest a discrimination of growth type, depending on the preparation method and the seedlayer/substrate type, into the Volker-Weber mechanism (3D island growth) and the StranskiKrastanov mechanism (2D layer, foliowed by 3D island growth). In several cases we have measured a perpendicular magnetization for films as thin as $5 \mathrm{~nm}$, as shown by AHE and in-plane VSM measurements; at around $10-20 \mathrm{~nm}$ the films exhibit a more or less in-plane magnetization, while thicker films (25-200 nm) again show an improved perpendicular characteristic. This is in agreement with calculations in ref. [21]. Finally we have shown the formation of small dot-like domains at intermediate fields for our high coercive films, by a technique that is strongly correlated to the replay part of the recording cycle. We have not observed strine domain formation.

\section{Acknowledgements}

The authors thank the Fourdation for Fundamental Research on Matter and the CAMST Action on Magnetic Storage Technology) EC stimulation project for their financial support. Furthermore we are indebted to $\mathrm{S}$. de Haan for performing the AHE measurements and A.M. Otter for making the SEM photographs. 


\section{References}

[1] W.J.M.A. Geerts, J.C. Lodder and Th.J.A. Popma, J. Magn. Magn. Mater. 104-107 (1992) 971.

[2] O. Lopez and D.A. Clark, J. Appl. Phys. 57 (1985) 3943.

[3] O. Lopez and D.A. Clark, IEEE Trans. Magn. MAG-21 (1985) 1401.

[4] Y. Nakamura, J. Magn. Soc. Jpn. 12 (1989) 33.

[5] J.C. Lodder, T. Wielinga and J. Worst, Thin Solid Films $101(1983) 61$.

[6] F.A. Pronk and J.C. Lodder, IEEE Trans. Magn. MAG24 (1988) 1744.

[7] M. Futamoto, Y. Honda, H. Kakibayashi, T. Shimotsu and Y. Uesaka, Jpn. Appl. Phys. 24 (1985) L460.

[8] M. Futamoto, Y. Honda, H. Kakibayashi and K. Yoshida, IEEE Trans. Magn. MAG-21 (1985) 1426.

[9] C. Byun, J.M. Sivertsen and J.H. Judy, J. Appl. Phys. 57 (1985) 3997.

[10] A. Kouchiyama, I. Sakai, I. Sumita, Y. Nakayama and M. Asanuma, IEEE Transl. J. Magn. Jpn. TJMJ-2 (1987) 106.

[11] J.C. Lodder and Li Cheng-Zhang, IEEE Trans. Magn. MAG-24 (1988) 1889.
[12] J.P.C. Bernards and C.P.G. Schrauwen, Thesis, University of Twente, Enschede, The Netherlands (1990) p. 196.

[13] S. de Haan, J.C. Lodder and Th.J.A. Popma, J. Magn. Suc. Jpn. 15 (1991) 349.

[14] B. Elm'rabat and Th.J.A. Popma, J. Magn. Magn. Mater. 87 (1990) 114.

[15] F. Enquist and A. Spetz, Thin Solid Films 145 (1986) 99.

[16] K. Reichelt, Vacuum 38 (1988) 1083.

[17] H. Cura and A. Lenhart, J. Magn. Magn. Mater. 83 (1990) 72.

[18] S.P. Murarka, Silicides for VLSI Applications (Academic Press, New York, 1983) p.72.

[19] C.P.G. Schrauwen, J.P.C. Bernards, R.W. de Bie, G.J.P. van Engelen, H.H. van Stel, V. Zieren and S.B. Luitjens, IEEE Trans. Magn. MAG-24 (1988) 1901.

[20] P. Heilmann, U. Kullmann and H. Haberkorn, J. de Phys. 46 (1985) C6-97.

[21] J.P.C. Bernards, G.J.P. van Engelen, C.P.G. Schrauwen and H.H. Stel, J. Magn. Magn. Mater. 78 (1989) L119.

[22] C. Kooy and U. Enz, Philips Res. Reports 15 (1960) 7.

[23] I. Simsova, R. Gemperle and J.C. Lodder, J. Magn. Magn. Mater. 95 (1991) 85.

[24] J.C. Lodder, D. Wind, G.E. van Dorssen, Th.J.A. Popma and A. Hubert, IEEE Trans. Magn. MAG-23 (1987) 214. 